\title{
Dissimilar alloys (AA6082/AA5083) joining by FSW and parametric optimization using Taguchi, grey relational and weight method
}

\author{
Sumit Jain $^{a^{*}}$, Neeraj Sharma ${ }^{\mathrm{b}}$ and Rajat Gupta ${ }^{\mathrm{c}}$
}

${ }^{a}$ Mechanical and Automation Engineering, HMR of Institute of Technology and Management, Hamidpur, New Delhi-110036, India

${ }^{b}$ Department of Mechanical Engineering, Maharishi Markandeshwar University, Mullana, Haryana-133207, India

${ }^{c}$ Department of Mechanical Engineering, R.P. Inderaprastha Institute of Technology, Karnal, Haryana-132001, India

\begin{tabular}{l}
\hline A R T I C L EI N F O \\
\hline Article history: \\
Received 26 June, 2017 \\
Accepted 22 October 2017 \\
Available online \\
23 October 2017 \\
\hline Keywords: \\
AA5083-O \\
AA6082 T-6 \\
Dissimilar alloys joining \\
FSW \\
GRA \\
Taguchi \\
Weight method
\end{tabular}

\section{Introduction}

Friction stir welding (FSW) was firstly investigated in 1991 by the welding Institute in the United Kingdom. By this welding technique, weld is made in solid phase, with no melting. During the FSW process (Gemme et al., 2009), a cylindrical tool being revolved and leisurely pushed into the mutual line where both specimens are butted together. Frictional heat is created in between the work piece and the resistant welding tool. The material softens due to frictional heat without attaining the dissolving point and permits traversing of tool besides the weld line (Fukuda, 2001; Mathers, 2002).

\footnotetext{
* Corresponding author. Tel.: +91-787-606-0308

E-mail addresses: sumitjain4@gmail.com (S. Jain) 
Okamura et al. (2004) studied a wide range of aluminium alloys, from 1000 to 8000 series, for FSW on similar and dissimilar material. It became clear from their research that joining dissimilar aluminium alloys, having different properties, is a challenging task. Shtrikman et al. (2005) analyzed the joining of dissimilar aluminium alloys D19 and 1420, focusing onthe phase composition, grain structure and the mass transfer rate in the joints. Soundararajan et al. (2007) studied AA5182 and AA6022aluminium alloys welding using FSW, considering the influence of plunge depth, rotational and transverse speed on the weld development. Behnagh et al. (2012) enhanced the wear resistance and hardness of AA 5083 by friction stir processing. Equi-axed grains can easily be induced by this process. Hassan et al. (2012) investigated aluminium reinforced with graphite and $\mathrm{SiC}$ composites, concluding that welded region have greater wear resistance as compared to the base metal due to micro-structural improvement. Mirjalili et al. (2013) also improved the grain structure of AA 2017 (artificially aged) by FSW.

Sarsilmaz et al. (2009) investigated the influence of input parameters viz. transverse speed, stirrer geometry and spindle rotational speed on UTS and the nugget hardness of friction stir welded AA 1050/AA 5083 alloys by ANOVA. Tanaka et.al (2010) considered the FSW of AA5083 and A6N01 for producing high quality dissimilar welds by evaluation of root bending testing and microstructure. Palanivel et al. (2011) considered the effect of process parameter such as TPP (five levels) and welding rate (three levels) over the tensile properties of AA-5083-H111 with AA6351-T6 alloy joints fabricated by FSW. Additional increases in the welding rate resulted in tensile strength diminishing. Baratzadeh et al. (2012) studied the micro-structural and mechanical properties of FSW butt joints between AA6082-T6 with AA6063-T6 through the Design of Experiments (DOE) methodology. Baratzadeh et al. (2013) studied the discontinuous friction stir lap-welding on AA-2024-T3 and 7075-T6 for crack initiation at friction stir weld exit holes in no-load transfer coupons. Constant amplitude fatigue tests were performed to find out the influence of different welding scenarios. Kandasamy et al. (2012) analyzed the influence of copper inclusion during the FSW of AA 6061/7075 (i.e. heterogeneous system), concluding that the intermetallic compounds $\left(\mathrm{Al}_{2} \mathrm{Cu}\right.$ etc.) formed during the FSW enhanced the joint strength by $24 \mathrm{MPa}$.

Bahemmat et al. (2011) analyzed the effect of FSW parameters on the characteristics of AA7075O / AA2024-T4 joints. Kumar and Raju (2012) studied different pin profiles influence onthe mechanical properties of FSW copper. The square pin profile gave the best result as compared to other profiles. Palanivel et al. (2012; 2014) studied different AA6351-T6/AA5083-H111 joints by FSW, using three different welding speeds $(36,63$ and $90 \mathrm{~mm} / \mathrm{min})$. These authors found that $63 \mathrm{~mm} / \mathrm{min}$ imparted better mechanical and metallurgical properties than other welding speeds. The fracture mode was observed to be a ductile fibrous fracture. Kundu and Singh $(2016$; 2017) worked on the joining of dissimilar Al alloys and investigated the mechanical characteristics after varying the input parameters at five different levels. They found that tool tilt angle is the prominent factor in the investigation of tensile strength and quality of surface. Gungor et al. (2012) studied the fatigue and mechanical properties of different alloys after FSW. The joint efficiency was nearly $65 \%$, while in case of similar alloy it has been found nearly $85 \%$. Low speed FSW shows higher fatigue limits. Esmaeili et al. (2014) worked on the elimination of welding defects viz. fragment and tunneling defect during FSW, by controlling the process parameters.

The above mentioned literature review shows a gap and therefore a research opportunity regarding the FSW of dissimilar alloys, namely AA 6082-T6 and AA 5083-O. In this sense, the present research work focused on FSW of AA 6082-T6 and AA 5083-O alloys. Firstly, single response optimizations were carried out by Taguchi's Technique for UTS and EL individually. Afterwards, both responses were optimized simultaneously by Grey relational analysis (GRA). Weight method is used in the Grey relation for giving the importance to any response. To a response of high importance is given a large weight value; while for a less important response, a smaller value of weight is provided, simultaneously. Equal weights (i.e. 0.5) are to be given in case of responses with equal importance. 


\section{Experimental Set-Up}

\subsection{Experimental Method}

A universal vertical milling machine was utilized for the current research work. The universal vertical milling machine tool has the following specifications:

Table Size $\quad: \quad 254 \mathrm{~mm} \times 1370 \mathrm{~mm}$

No. of Speed : $\quad$ 8, Minimum 70 R.P.M. Maximum 4600 R.P.M.

Main Motor Spindle: 3HP

Table 1

Chemical Composition of AA 6082-T6 and AA-5083-T6

\begin{tabular}{ccccc}
\hline \multirow{2}{*}{ Sr. No. } & \multicolumn{2}{c}{ AA 6082-T6 } & \multicolumn{2}{c}{ AA 5083-O } \\
\cline { 2 - 5 } & Elements & Observation (\%) & Elements & Observation (\%) \\
\hline 1 & Copper & 0.051 & Magnesium & 4.830 \\
2 & Magnesium & 0.800 & Manganese & 0.551 \\
3 & Silicon & 1.100 & Iron & 0.336 \\
4 & Iron & 0.263 & Silicon & 0.290 \\
5 & Manganese & 0.552 & Nickel & 0.007 \\
6 & Nickel & 0.010 & Zinc & 0.035 \\
7 & Zinc & 0.039 & Lead & 0.030 \\
8 & Lead & 0.012 & Tin & 0.010 \\
9 & Tin & 0.009 & Titanium & 0.050 \\
10 & Titanium & 0.035 & Chromium & 0.100 \\
11 & Chromium & 0.050 & Copper & 0.050 \\
12 & Aluminium & 97.06 & Aluminium & 93.700 \\
\hline
\end{tabular}

Table 2

UTS and \% Elongation For Base material (AA 5083-O and AA 6082-T6)

\begin{tabular}{ccc}
\hline Base Material & UTS (MPa) & Elongation (cm) \\
\hline AA 5083-O & 288.33 & 1.7 \\
AA 6082-T6 & 333 & 1.8 \\
\hline
\end{tabular}

AA 6082-T6 and 5083-O of 6-mm thickness were used to fabricate the joints (where ' $\mathrm{T} 6$ ' stands for tempered and ' $\mathrm{O}$ ' stands for annealed soft). The Sheets were cut to the requisite size $(150 \times 60 \times 6 \mathrm{~mm})$ by power hacksaw and then grinding was done to eliminate burrs. The chemical composition of AA 6082-T6 and AA-5083-O is given in Table 1. AA 6082 and AA 5083 are widely utilized in sub-marine and aero-space industries due to their high strength and light weight. AA 6082-T6 is Al-Mg-Si alloys containing manganese to enhance toughness and ductility while AA 5083-O is Al-Mg alloy. Table 2 gives the UTS and EL of the base material for AA 5083-O and AA 6082-T6. These values were measured with the help of universal testing machine according to ASTM guidelines.

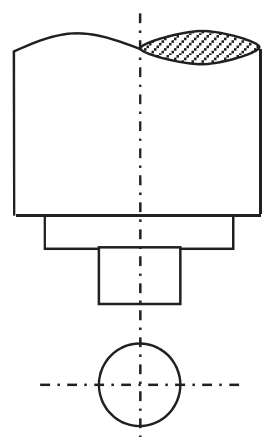

Cylindrical(1)

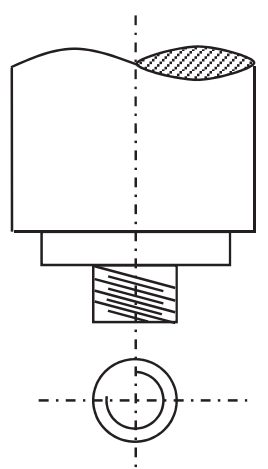

Threaded Cylindrical $(2)$

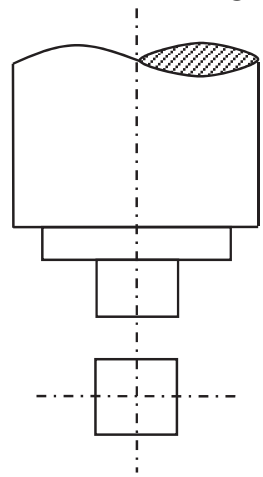

(2) Square(3)

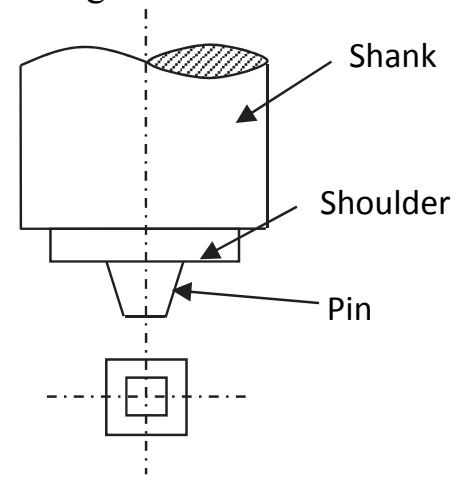

Trapezoidal(4)

Fig. 1 Different profiles of the tool pin used for FSW 
The material used for the FSW tool was high carbon steel due to its good machinability, good thermal fatigue resistance. Other properties, which make it suitable during aluminium alloy joining are resistance to deformation and abrasion. The tools were consisted of tool shank, tool shoulder and tool pin.

The cylindrical profiled tool shoulder was used for producing heat and different pin profiles were used to stir the material during welding. The different tool pin profiles used such as simple cylindrial, threaded cylindrical, Square and trapezoidal were shown in Fig. 1.

Table 3

Control variables and their levels

\begin{tabular}{|c|c|c|c|c|c|c|c|}
\hline S. No & Parameters & Units & Levels & Level 1 & Level 2 & Level 3 & Level 4 \\
\hline A & Tool rotation speed & $\mathrm{rpm}$ & 4 & 1200 & 1950 & 3080 & 4600 \\
\hline B & welding speed & $\mathrm{mm} / \mathrm{min}$ & 4 & 20 & 25 & 30 & 35 \\
\hline $\mathrm{C}$ & Tool pin profile ${ }^{*}$ & - & 4 & 1 & 2 & 3 & 4 \\
\hline $\mathrm{D}$ & Tool shoulder dia. & $\mathrm{mm}$ & 4 & 14 & 16 & 18 & 20 \\
\hline
\end{tabular}

Table 4

Taguchi's L ${ }_{16}$ Orthogonal Array for UTS \& EL

\begin{tabular}{ccccccc}
\hline $\begin{array}{c}\text { Exp. } \\
\text { No. }\end{array}$ & $\begin{array}{c}\text { Tool } \\
\text { rotation } \\
\text { speed(A) }\end{array}$ & $\begin{array}{c}\text { Welding } \\
\text { speed (B) }\end{array}$ & $\begin{array}{c}\text { Tool pin } \\
\text { profile (C) }\end{array}$ & $\begin{array}{c}\text { Tool } \\
\text { shoulder } \\
\text { dia.(D) }\end{array}$ & $\begin{array}{c}\text { Ultimate tensile } \\
\text { strength (MPa) }\end{array}$ & $\begin{array}{c}\text { Elongation } \\
\text { (cm) }\end{array}$ \\
\hline 1 & 1200 & 20 & 1 & 14 & 230.20 & 0.75 \\
\hline 2 & 1200 & 25 & 2 & 16 & 243.85 & 0.75 \\
3 & 1200 & 30 & 3 & 18 & 246.86 & 0.80 \\
\hline 4 & 1200 & 35 & 4 & 20 & 243.08 & 0.80 \\
\hline 5 & 1950 & 20 & 2 & 18 & 225.00 & 0.85 \\
\hline 6 & 1950 & 25 & 1 & 20 & 228.66 & 0.95 \\
\hline 7 & 1950 & 30 & 4 & 14 & 240.86 & 0.70 \\
\hline 8 & 1950 & 35 & 3 & 16 & 249.50 & 0.75 \\
\hline 9 & 3080 & 20 & 3 & 20 & 210.64 & 1.05 \\
10 & 3080 & 25 & 4 & 18 & 225.74 & 0.90 \\
11 & 3080 & 30 & 1 & 16 & 235.74 & 0.90 \\
\hline 12 & 3080 & 35 & 2 & 14 & 234.86 & 0.80 \\
\hline 13 & 4600 & 20 & 4 & 16 & 201.60 & 0.95 \\
\hline 14 & 4600 & 25 & 3 & 14 & 214.90 & 0.90 \\
15 & 4600 & 30 & 2 & 20 & 212.45 & 1.00 \\
\hline 16 & 4600 & 35 & 1 & 18 & 218.26 & 0.90 \\
\hline
\end{tabular}

The pin profile cross section used in the current research was $6 \mathrm{~mm}$ diameter in cylindrical tool pin, $6 \mathrm{~mm}$ diameter with $1 \mathrm{~mm}$ pitch in threaded cylindrical, $6 \mathrm{~mm}$ side in case of a square tool pin, and in trapezoidal $6 \mathrm{~mm}$ of base with tapered to $3 \mathrm{~mm}$ at the tip. After manufacturing the tools, the pin of the tools was annealed for strengthening the tool tip. The control parameters viz.: TRS, WS, TPP and SD 
were selected (by literature review and machine tool capacity) for optimizing the various response parameters (UTS and EL). Taguchi's design of experiment was used for the planning of experiments using $\mathrm{L}_{16}$ orthogonal array (Roy, 1990). In light of the objective, the levels for each factor have been decided to keep in view the machine tool capacity of the milling machine used for FSW. Table 3 details the different control variables and their levels.

The process parameters, those were kept constant during the experimentation, are axial load- $2 \mathrm{kN}$; final plunge depth of tool pin $-5.8 \mathrm{~mm}$; tool pin diameter- $6 \mathrm{~mm}$; tool tilt angle- $1^{\mathrm{o}}$; tool pin length$5.8 \mathrm{~mm}$; cooling medium-Normal air; Tool material-high carbon steel, mode of FSW- position control. For the testing of welded pieces on a universal testing machine ASTM guidelines were followed. Table 4 gives the values of UTS and elongation against the input parameter setting for $\mathrm{L}_{16}$ orthogonal array. Table 5 shows the signal to noise $(\mathrm{S} / \mathrm{N})$ value for UTS and EL.

Table 5

Data Summary for Ultimate Tensile Strength and Elongation

\begin{tabular}{ccccc}
\hline Sr. NO & $\begin{array}{c}\text { Ultimate Tensile } \\
\text { Strength (MPa) }\end{array}$ & $\begin{array}{c}\text { Ultimate Tensile } \\
\text { Strength (S/N Ratio) }\end{array}$ & $\begin{array}{c}\text { Elongation } \\
(\mathbf{c m})\end{array}$ & $\begin{array}{c}\text { Elongation (S/N } \\
\text { Ratio) }\end{array}$ \\
\hline 1 & 230.2 & 47.24211 & 0.75 & 2.49 \\
2 & 243.85 & 47.74246 & 0.75 & 2.49 \\
3 & 246.86 & 47.84901 & 0.80 & 1.93 \\
4 & 243.08 & 47.71498 & 0.80 & 1.93 \\
5 & 225 & 47.04365 & 0.85 & 1.41 \\
6 & 228.66 & 47.1838 & 0.95 & 0.44 \\
7 & 240.86 & 47.63529 & 0.70 & 3.09 \\
8 & 249.5 & 47.94141 & 0.75 & 2.49 \\
9 & 210.64 & 46.47082 & 1.05 & -0.42 \\
10 & 225.74 & 47.07217 & 0.90 & 0.91 \\
11 & 235.74 & 47.44867 & 0.90 & 0.91 \\
12 & 234.86 & 47.41618 & 0.80 & 1.93 \\
13 & 201.6 & 46.08981 & 0.95 & 0.44 \\
14 & 214.9 & 46.64473 & 0.90 & 0.91 \\
\hline 15 & 212.45 & 46.54513 & 1.00 & 0.00 \\
\hline 16 & 218.26 & 46.77948 & 0.90 & 0.91 \\
\hline Average & 228.8875 & 47.17623 & 0.85 & 1.37 \\
\hline Maximum & 249.5 & 47.94141 & 1.05 & -0.42 \\
\hline Minimum & 201.6 & 46.08981 & 0.70 & 3.09 \\
\hline
\end{tabular}

Table 6

Response Table for Ultimate Tensile Strength and Elongation (Means)

\begin{tabular}{ccccccc}
\hline \multirow{2}{*}{ Level } & \multicolumn{3}{c}{ Ultimate Tensile Strength } & \multicolumn{3}{c}{ Elongation } \\
\cline { 2 - 7 } & A & B & D & A & B & D \\
\hline 1 & $\mathbf{2 4 1 . 0}$ & 216.9 & 230.2 & $\mathbf{0 . 7 7 5 0}$ & 0.9000 & $\mathbf{0 . 7 8 7 5}$ \\
2 & 236.0 & 228.3 & $\mathbf{2 3 2 . 7}$ & 0.8125 & 0.8750 & 0.8375 \\
3 & 226.7 & 234.0 & 229.0 & 0.9125 & 0.8500 & 0.8625 \\
4 & 211.8 & $\mathbf{2 3 6 . 4}$ & 223.7 & 0.9375 & $\mathbf{0 . 8 1 2 5}$ & 0.9500 \\
\hline Delta & 29.2 & 19.6 & 9.0 & 0.1625 & 0.0875 & 0.1625 \\
Rank & 1 & 2 & 3 & 1 & 3 & 2 \\
\hline
\end{tabular}

\section{Analysis of Result for Single Response Optimization}

The major process parameters affecting the UTS can be analyzed ANOVA. The optimum condition is shown by peak points (Fig. 2a) in the plots (Byrne and Taguchi, 1987; Ross, 1988; Sharma and Khanna, 2011; Sharma et al., 2016). Fig. 2 (a) and Fig. (b) shows the influence of different input 
parameters on UTS and EL. The analysis is done using "MINITAB 16" exclusively used for the design of experiment purposes.

The ANOVA has been executed to recognize the major parameters and to enumerate their outcomes on the performance measures. ANOVA indicate that which parameters influence the response most (Barker, 1990). Response Table for UTS and EL is given in Table 6 for investigating the optimal parameter setting. ANOVA for Means data are given in Tables 7-8.

An optimal level of significant parameters i.e. TRS $\left(\mathrm{A}_{1}\right)$, WS $\left(\mathrm{B}_{4}\right)$ and $\mathrm{SD}\left(\mathrm{D}_{2}\right)$ in Table 6 and Fig. 3 (a) are used to predict the mean value of UTS. The predicted mean of the UTS is determined (Roy, 1990; Kumar, 1993) by Eq. (1).

$$
\mu_{\mathrm{UTS}}=\mathrm{A}_{1}+\mathrm{B}_{4}+\mathrm{D}_{2}-2 \mathrm{~T}
$$

where, $\mathrm{T}=$ overall mean of UTS $=(\Sigma \mathrm{TS}) / 16=228.8875 \mathrm{MPa}$

Also, UTS are taken from the Table 4 and the values of $\mathrm{A}_{1}, \mathrm{~B}_{4}$, and $\mathrm{D}_{2}$ are taken from the Table 6 . Substituting the values of different terms in the equation (1), $\mu_{\mathrm{UTS}}=241+236.40+232.70-2(228.8875)=252.325 \mathrm{MPa}$

$$
246.014<\mu_{\mathrm{UTS}}<258.636
$$

The optimal levels of control factors are as given:

First level of TRS $\left(\mathrm{A}_{1}\right): 1200 \mathrm{RPM}$

Second level of WS (B4): $35 \mathrm{~mm} / \mathrm{min}$

Fourth level of SD $\left(\mathrm{D}_{2}\right): 16 \mathrm{~mm}$

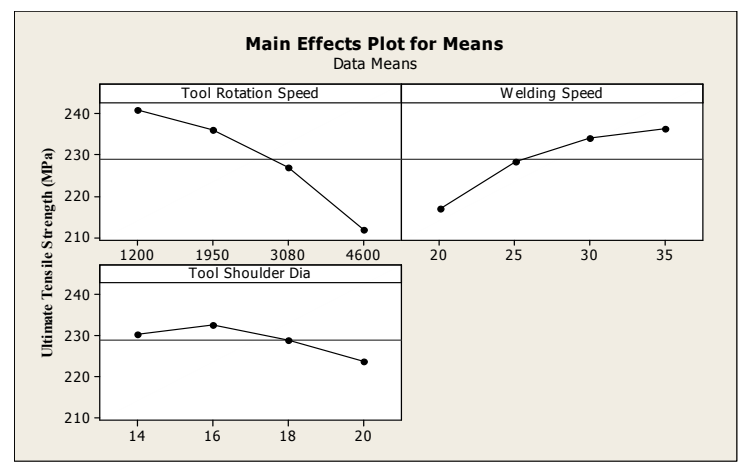

Fig. 2 (a) Effects of Process Parameters on Ultimate Tensile Strength (Means)

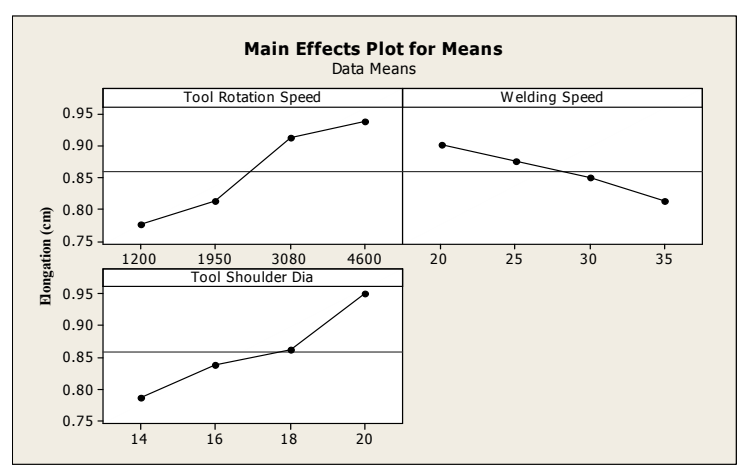

Fig. 2 (b) Effects of Process Parameters on Elongation (Means)

Elongation is predicted at suggested levels of input parameters TRS $\left(\mathrm{A}_{1}\right)$ and WS $\left(\mathrm{B}_{4}\right)$ and SD $\left(\mathrm{D}_{1}\right)$ (Table 6 and Fig. 3 (b)). The predicted mean of the EL determined from Eq. (2).

$$
\mu_{\mathrm{EL}}=\mathrm{A}_{1}+\mathrm{B}_{4}+\mathrm{D}_{1}-2 \mathrm{~T}
$$

$\mu_{\mathrm{EL}}=0.7750+0.8125+0.7875-2(0.859)=0.655 \mathrm{~cm}$

where $\mathrm{T}=0.859 \quad$ (Table 4$)$

The predicted value at $95 \%$ confidence level is:

Mean $\mu_{\mathrm{EL}}-\mathrm{CI}_{\mathrm{CE}}<$ Mean $\mu_{\mathrm{EL}}<$ Mean $\mu_{\mathrm{EL}}+\mathrm{CI}_{\mathrm{CE}}$

$0.557<\mu_{\mathrm{EL}}<0.753$

The optimal levels of control factors are as given:

First level of TRS $\left(\mathrm{A}_{1}\right)$ : $1200 \mathrm{RPM}$

Fourth level of WS $\left(B_{4}\right): 35 \mathrm{~mm} / \mathrm{min}$

First level of SD $\left(D_{1}\right): 14 \mathrm{~mm}$ 


\subsection{Discussion of the results}

\subsubsection{Effect on UTS}

From Table 7, it is found that the WS is the most influencing factor for increasing the tensile strength, SD is the $2^{\text {nd }}$ major contributing parameter, TRS is the $3^{\text {rd }}$ parameter. It is also clear from the Fig. 2 (a) that the UTS increase as the WS is increased. But with the increase of tool rotation speed, UTS decreases. The reason behind this is that when the WS increases the heat input in the thermo mechanically affected zone (TMAZ) and heat affected zone (HAZ) reduces due to which the ductility of material in TMAZ do not increase but UTS increases (Hassan et al., 2012). By increasing the TRS, the heat input in the TMAZ and HAZ increases due to which ductility of material increases and finally UTS decreases. From the Fig. 2 (a), the UTS first increases from $14 \mathrm{~mm}$ to $16 \mathrm{~mm}$ and then decreases because of the increase in length of TMAZ and HAZ.

Table 7

Pooled Analysis of Variance for Ultimate Tensile Strength (Means)

\begin{tabular}{ccccccc}
\hline Source & $\mathbf{D F}^{*}$ & $\mathbf{S S}^{*}$ & $\mathbf{M S}^{*}$ & $\mathbf{F}$ & $\mathbf{P}^{*}$ & PC $^{*}$ \\
\hline Tool Rotation Speed & 3 & 1975.19 & 658.398 & 160.92 & 0.000 & 64.08 \\
Welding Speed & 3 & 910.97 & 303.657 & 74.22 & 0.000 & 29.55 \\
Tool Shoulder Dia & 3 & 171.60 & 57.201 & 13.98 & 0.004 & 05.67 \\
Residual Error & 6 & 24.55 & 4.092 & & & 0.797 \\
\hline Total & 15 & 3082.32 & & &
\end{tabular}

*DF-Degree of Freedom; SS-Sum of Square; MS-Mean Square; PC-Percentage contribution

Table 8

Pooled Analysis of Variance for Elongation (Means)

\begin{tabular}{clccccc}
\hline Source & $\mathbf{D F}^{*}$ & $\mathbf{S S}^{*}$ & $\mathbf{M S}^{*}$ & $\mathbf{F}$ & $\mathbf{P}$ & PC $^{*}$ \\
\hline Tool Rotation Speed & 3 & 0.072969 & 0.024323 & 4.58 & 0.001 & 48.29 \\
Welding Speed & 3 & 0.016719 & 0.005573 & 5.63 & 0.035 & 11.06 \\
Tool Shoulder Dia & 3 & 0.055469 & 0.018490 & 18.68 & 0.002 & 36.71 \\
Residual Error & 6 & 0.005937 & 0.000990 & & & 3.93 \\
\hline Total & 15 & 0.151094 & & & & \\
\hline
\end{tabular}

${ }^{*}$ DF-Degree of Freedom; SS-Sum of Square; MS-Mean Square; PC-Percentage contribution

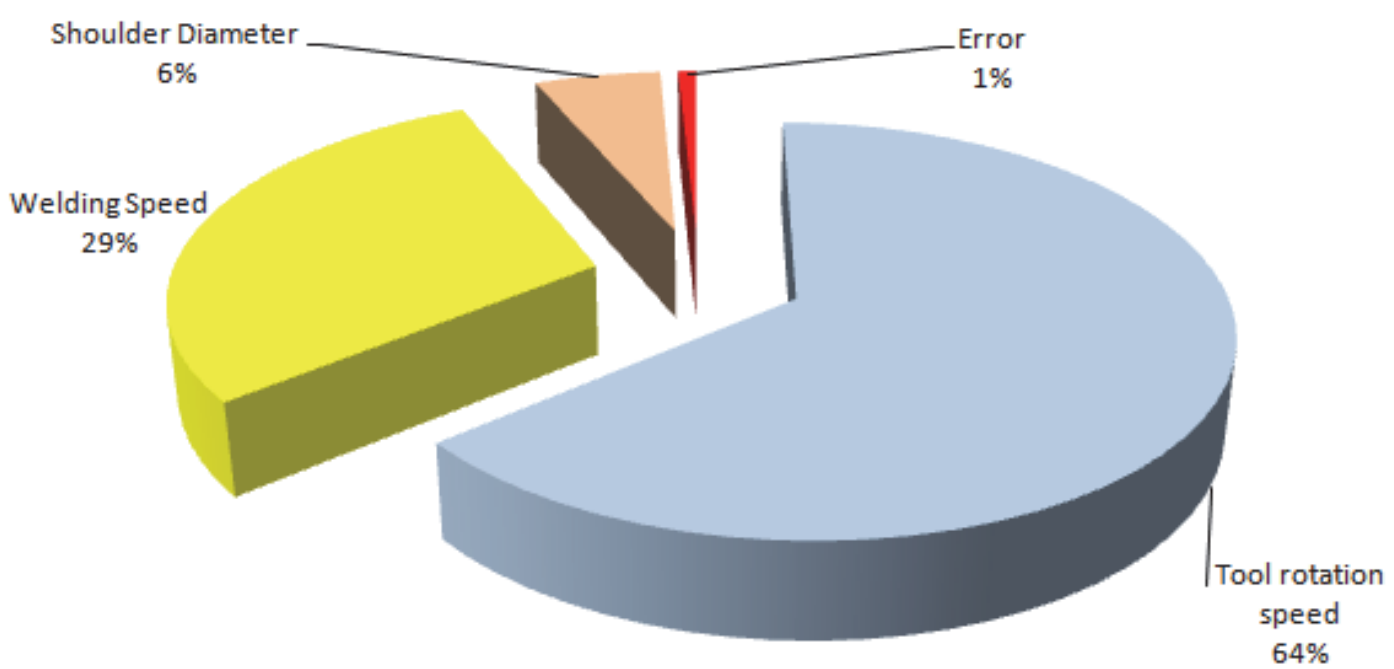

Fig. 3 (a) Percentage Contribution of Process Parameters on UTS 
In order to estimate the contribution of each factor towards the variation of joining performance in terms of UTS for FSW of AA 6082-T6 and AA 5083-O, the ANOVA result (Table 7) gives that TRS is the most effective parameter with a contribution of $64.08 \%$. The percent contribution of WS on UTS is $29.55 \%$, followed by the tool SD (5.67 \%) as depicted in Fig. 3 (a).

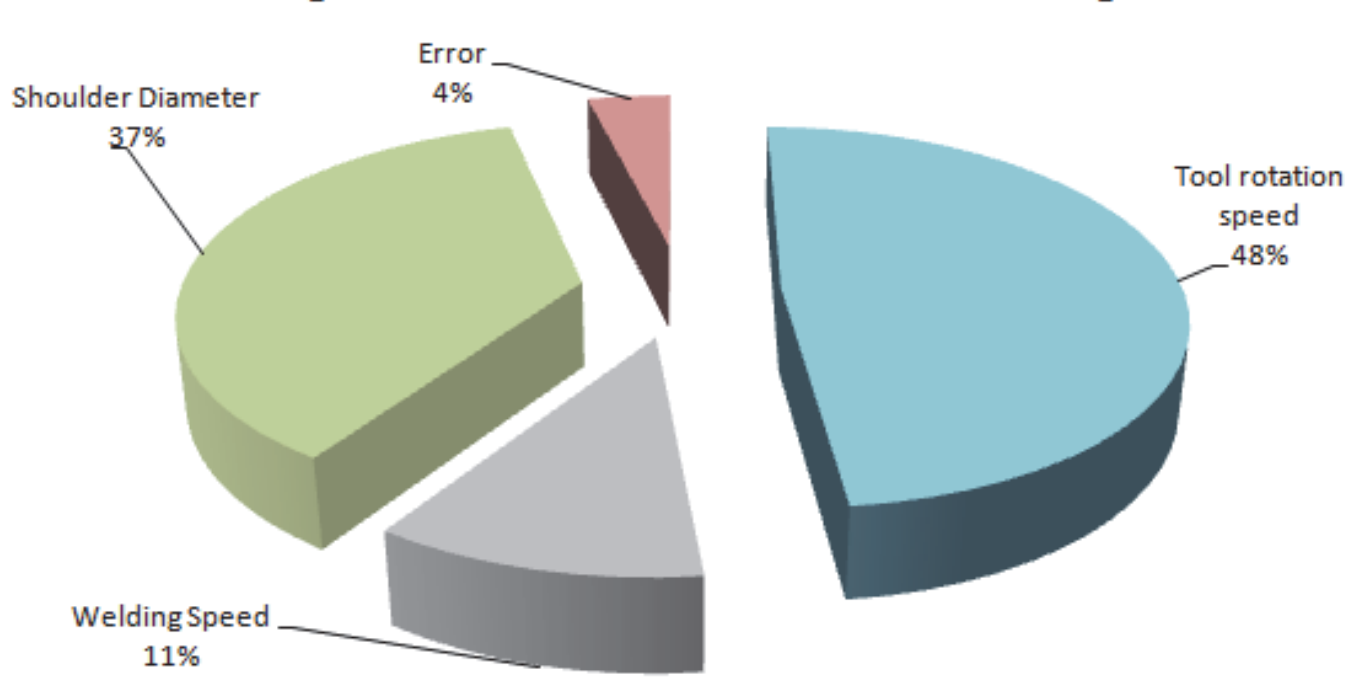

Fig. 3 (b) Percentage Contribution of Process Parameters on EL

\subsubsection{Effect on Elongation}

The most significant factor for the elongation is tool rotational speed whereas the effect of WS and tool shoulder dia. was also significant. From the Fig. 3b, the optimal Elongation has been recorded with TRS (at level 1), WS (at level 4), SD (at level 1). In FSW the TRS is a more significant factor for optimizing the elongation as compared to other parameter i.e. WS, SD and TPP with regard to elongation. It is depicted from Fig. $2 b$ that by increasing the TRS, elongation increases. This is due to increase of the ductility on TMAZ and HAZ, because of more heat is added at higher value of TRS. By increasing the WS; the heat addition is reduced in the welding region (TMAZ and HAZ) due to which ductility decreases and hence the elongation are decreased. By increasing the SD, the length of welding region increased due to which elongation found to be increased.

For the contribution of each factor towards the variation of welding performance in terms of elongation, ANOVA was conducted. The ANOVA test summary for Elongation has been recorded for the average response (Table 8). The ANOVA results also showed that TRS is the most effective parameter with a contribution of $48.29 \%$. The percent contribution tool SD and WS is $36.71 \%$ and $11.06 \%$, respectively (Fig. 3b). Hence the elongation is affected by the TRS, SD and WS. It is found from this discussion that the elongation enhances by increasing TRS and tool shoulder diameter.

\section{Multi Response Optimization}

Taguchi's technique is meant for single performance characteristic optimization but sometime a balance is to be kept between the two responses, especially if both are opposite in nature viz. one is "larger is better" and another one is "smaller the better". In these types of problems, an optimal setting of parameters can be obtained by integrating some other technique like Taguchi Grey relational analysis (GRA). 
Deng $(1982 ; 1989)$ suggested Grey relational analysis by generating a cumulative value known as grey relational grade. Two different ways can be adopted for obtaining the grade value like one method using the mean value of response and another method using the $\mathrm{S} / \mathrm{N}$ ratio.

Antony (2001) used Taguchi's quality loss function for the optimization of numerous responses in manufacturing processes. The coefficient value for each response is evaluated by GRA procedure which is known as the Grey relational coefficient (GRC). The weighted values of these coefficients are termed as grey relational grade (GRG) and are employed for the further analysis by Taguchi's experimental plan. A mean value and $\mathrm{S} / \mathrm{N}$ ratio of UTS and elongation is used for multi response optimization. Mean values and $\mathrm{S} / \mathrm{N}$ ratios of UTS and EL are shown in Table 5. Also response value in some cases varies in microns, while in some cases it is in terms of 1000. Data pre-processing is necessary to convert it in between 0 and 1 . For the "larger-the-better" response viz. UTS, the original sequence follows:

$$
\chi_{i}^{*}(k)=\frac{x_{i}(k)-\min x_{i}(k)}{\max x_{i}(k)-\min x_{i}(k)}
$$

Table 10

Data pre-processing and deviational sequence of mean values of experimental result

\begin{tabular}{ccccc}
\hline Exp No & \multicolumn{2}{c}{ Data Pre-processing } & \multicolumn{2}{c}{ Deviation sequence } \\
& UTS & EL & UTS & EL \\
\hline Reference sequence & $\mathbf{1 . 0 0 0}$ & $\mathbf{1 . 0 0 0}$ & $\Delta_{n}^{i}(1)$ & $\Delta_{n}^{i}(2)$ \\
1 & 0.622 & 0.829 & 0.377 & 0.170 \\
2 & 0.892 & 0.829 & 0.107 & 0.170 \\
3 & 0.950 & 0.670 & 0.049 & 0.329 \\
4 & 0.877 & 0.670 & 0.122 & 0.329 \\
5 & 0.515 & 0.521 & 0.484 & 0.478 \\
6 & 0.590 & 0.246 & 0.409 & 0 \\
7 & 0.834 & 1 & 0.165 & 0.170 \\
8 & 1 & 0.829 & 0 & 1 \\
9 & 0.205 & 0 & 0.794 & 0.619 \\
10 & 0.530 & 0.380 & 0.469 & 0.619 \\
11 & 0.733 & 0.380 & 0.266 & 0.329 \\
12 & 0.716 & 0.670 & 0.283 & 0.753 \\
13 & 0 & 0.246 & 1 & 0.619 \\
14 & 0.299 & 0.380 & 0.700 & 0.879 \\
15 & 0.245 & 0.120 & 0.754 & 0.619 \\
\hline
\end{tabular}

where, $x_{i}(k)$ - sequence subsequent to the data pre-processing, $x_{0}^{*}(\mathrm{k})$ - Original sequence of SN ratio, $\mathrm{k}=1$ for UTS; $\mathrm{i}=1,2,3 \ldots, 16$ for experiment numbers 1 to 16 (Caydas and Hascalik, 2008; Khanna et al., 2015; Jangra et al., 2016). When the "smaller-the-better" is a characteristic of the real sequence, then the real sequence follows:

$$
\chi_{i}^{*}(k)=\frac{\max x_{i}(k)-x_{i}(k)}{\max x_{i}(k)-\min x_{i}(k)},
$$

$\mathrm{k}=2$ for elongation $\mathrm{i}=1,2,3 \ldots, 16$ for experiment numbers 1 to 16 . All the sequences are listed in Table 10 after data pre-processing. The absolute difference of GRC $\left(\xi_{i}(k)\right)$ and array $\Delta_{0}^{i}(\mathrm{k})$ is computed from the analysis model of GRA are shown in Table 10. 


\section{Table 11}

Grey relational Coefficient

\begin{tabular}{ccc}
\hline S. No. & \multicolumn{2}{c}{ Grade Relational Coefficient } \\
\hline Comparability Sequence & Ultimate Tensile Strength & Elongation \\
\hline 1 & 0.569 & 0.746 \\
2 & 0.823 & 0.746 \\
3 & 0.909 & 0.602 \\
4 & 0.803 & 0.602 \\
5 & 0.507 & 0.510 \\
6 & 0.549 & 0.398 \\
7 & 0.751 & 1 \\
8 & 1 & 0.746 \\
9 & 0.386 & 0.333 \\
10 & 0.515 & 0.446 \\
11 & 0.652 & 0.446 \\
12 & 0.638 & 0.602 \\
13 & 0.333 & 0.398 \\
14 & 0.416 & 0.446 \\
15 & 0.398 & 0.362 \\
\hline
\end{tabular}

The GRC is defined as follows:

$$
\xi_{i}^{*}(k)=\frac{\Delta_{\min }+\xi \cdot \Delta_{\max }}{\Delta_{o i}(k)+\xi \cdot \Delta_{\max }}
$$

$\xi_{i}(k)-\mathrm{GRC}$,

$\gamma$ - GRG for all performance characteristics,

$\zeta$ - identification coefficient,

$\Delta_{0}^{i}(\mathrm{k})$ - deviation sequence of the comparability sequence $x_{0}^{*}(\mathrm{k})$.

$$
\Delta_{o i}(k)=\left|x_{o}^{*}(k)-x_{i}^{*}(k)\right|
$$

Now, $\Delta_{0}^{i}(\mathrm{k})$ - deviation sequence

$\mathrm{X}_{\mathrm{i}}(\mathrm{k})$ - comparability sequence

$x_{0}^{*}(\mathrm{k})$ - reference sequence as shown in Table 11 .

After obtaining the GRC, the GRG is determined by using weight method, like if UTS is given more preference than EL, then GRC of UTS is multiplied by 0.7 and another coefficient multiplied by 0.3. If EL is given more preference, then it is multiplied by 0.7 and UTS multiplied by 0.3 . In case of equal preference both are multiplied by 0.5 and then added as given in Table 12 .

$$
\gamma_{i}=w_{1} \xi_{1}+w_{2} \xi_{2}
$$


where $\gamma_{i}$ is the GRG for the $i_{\text {th }}$ experiment. GRG for every experiment using $L_{16}$ orthogonal array were shown in Table 12. The superior GRG denotes that respective experimental result is approaching the ideally normalized value. When equal weight is given to both responses (i.e. 0.5) or UTS is given minimum weight (i.e. 0.3), EL is given maximum weight $(0.7)$, then the seventh trial run gives the maximum grade value. While when UTS is given maximum weight $(0.7)$ and EL is given minimum weight (i.e. 0.3 ), then the $8^{\text {th }}$ trial run gives maximum grade value. The maximum values of grades were represented by bold and highlighted text in Table 12 .

Table 12

Grey Relational Grade according to Different Weights

\begin{tabular}{cccccccccc}
\hline \multirow{2}{*}{ Sr. No. } & \multicolumn{3}{c}{$\mathbf{W}_{\mathbf{1}}=\mathbf{W}_{\mathbf{2}}=\mathbf{0 . 5}$} & \multicolumn{3}{c}{$\mathbf{W}_{\mathbf{1}}=\mathbf{0 . 7} ; \mathbf{W}_{\mathbf{2}}=\mathbf{0 . 3}$} & \multicolumn{3}{c}{$\mathbf{W}_{\mathbf{1}}=\mathbf{0 . 3} ; \mathbf{W}_{\mathbf{2}}=\mathbf{0 . 7}$} \\
\cline { 2 - 10 } & UTS 0.5 & $\mathbf{E L ~ 0 . 5}$ & GRG & UTS 0.7 & EL 0.3 & GRG & UTS 0.3 & EL 0.7 & GRG \\
\hline $\mathbf{1}$ & 0.2848 & 0.3730 & 0.6579 & 0.3988 & 0.2238 & 0.6226 & 0.1709 & 0.5223 & 0.6932 \\
$\mathbf{2}$ & 0.4116 & 0.3730 & 0.7846 & 0.5762 & 0.2238 & 0.8000 & 0.2469 & 0.5223 & 0.7692 \\
$\mathbf{3}$ & 0.4546 & 0.3014 & 0.7561 & 0.6365 & 0.1809 & 0.8173 & 0.2728 & 0.4220 & 0.6948 \\
$\mathbf{4}$ & 0.4017 & 0.3014 & 0.7032 & 0.5624 & 0.1809 & 0.7433 & 0.2410 & 0.4220 & 0.6631 \\
$\mathbf{5}$ & 0.2538 & 0.2554 & 0.5092 & 0.3554 & 0.1532 & 0.5086 & 0.1523 & 0.3576 & 0.5099 \\
$\mathbf{6}$ & 0.2750 & 0.1995 & 0.4745 & 0.3850 & 0.1197 & 0.5047 & 0.1650 & 0.2793 & 0.4443 \\
$\mathbf{7}$ & 0.3758 & 0.5000 & $\mathbf{0 . 8 7 5 8}$ & 0.5261 & 0.3000 & 0.8261 & 0.2255 & 0.7000 & $\mathbf{0 . 9 2 5 5}$ \\
$\mathbf{8}$ & 0.5000 & 0.3730 & 0.8730 & 0.7000 & 0.2238 & $\mathbf{0 . 9 2 3 8}$ & 0.3000 & 0.5223 & 0.8223 \\
$\mathbf{9}$ & 0.1932 & 0.1667 & 0.3598 & 0.2704 & 0.1000 & 0.3704 & 0.1159 & 0.2333 & 0.3492 \\
$\mathbf{1 0}$ & 0.2579 & 0.2233 & 0.4811 & 0.3610 & 0.1340 & 0.4950 & 0.1547 & 0.3126 & 0.4673 \\
$\mathbf{1 1}$ & 0.3263 & 0.2233 & 0.5496 & 0.4568 & 0.1340 & 0.5908 & 0.1958 & 0.3126 & 0.5083 \\
$\mathbf{1 2}$ & 0.3190 & 0.3014 & 0.6205 & 0.4466 & 0.1809 & 0.6275 & 0.1914 & 0.4220 & 0.6134 \\
$\mathbf{1 3}$ & 0.1667 & 0.1995 & 0.3662 & 0.2333 & 0.1197 & 0.3530 & 0.1000 & 0.2793 & 0.3793 \\
$\mathbf{1 4}$ & 0.2083 & 0.2233 & 0.4315 & 0.2916 & 0.1340 & 0.4255 & 0.1250 & 0.3126 & 0.4375 \\
$\mathbf{1 5}$ & 0.1993 & 0.1812 & 0.3806 & 0.2791 & 0.1087 & 0.3878 & 0.1196 & 0.2537 & 0.3733 \\
$\mathbf{1 6}$ & 0.2217 & 0.2233 & 0.4450 & 0.3104 & 0.1340 & 0.4444 & 0.1330 & 0.3126 & 0.4456 \\
\hline
\end{tabular}

\subsection{Performing ANOVA}

A response table for means and ANOVA is shown in Table 13 and 14 respectively, and graphs of GRG (equal preference to responses) are represented in Fig. 4.

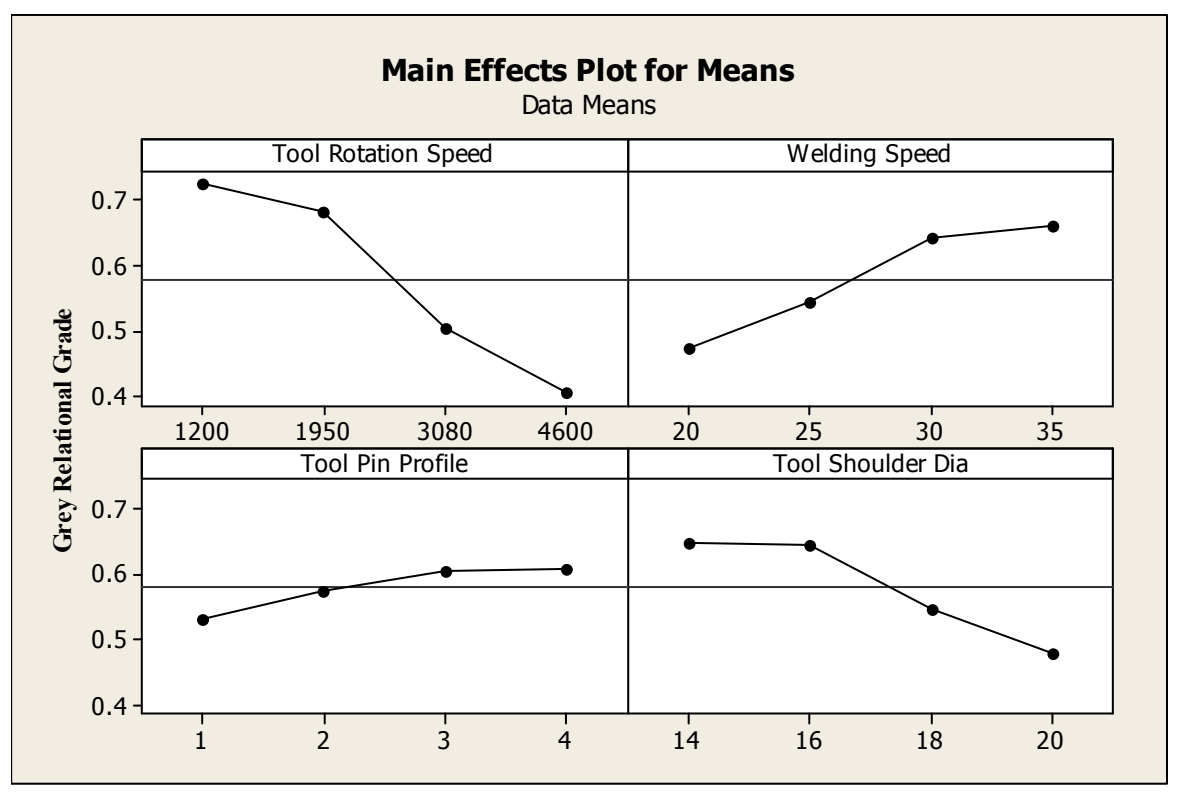

Fig. 4 Graphs of Grey Relational Grade value 
It clearly illustrates from Table 14 that WS, TRS and Tool SD are the major contributing parameters to influence GRG, so improve UTS and weld quality. Excluding these three parameters TPP is also significant. The effect of the significant parameters is considered to predict the optimal value of every response characteristic. The average values of the response variables must lie within the $95 \%$ confidence interval, obtained from confirmation experiments $\mathrm{CI}_{\mathrm{CE}}$. Estimated GRG computed as;

$$
\hat{\gamma}=\gamma_{m}+\sum_{i=1}^{v}\left(\gamma_{i}-\gamma_{m}\right)
$$

where $\gamma_{\mathrm{m}}$ total mean of GRG,

$\gamma_{\mathrm{i}}$ mean GRG at optimum level,

$\mathrm{v}-$ No. of process parameters.

Table 13

Response Table for Grey Relational Grade

\begin{tabular}{ccccc}
\hline Level & Tool Rotation Speed & Welding Speed & Tool Pin Profile & Tool Shoulder Dia \\
\hline $\mathbf{1}$ & $\mathbf{0 . 7 2 5 4}$ & 0.4733 & 0.5317 & $\mathbf{0 . 6 4 6 4}$ \\
$\mathbf{2}$ & 0.6831 & 0.5429 & 0.5737 & 0.6433 \\
$\mathbf{3}$ & 0.5027 & 0.6405 & 0.6051 & 0.5479 \\
$\mathbf{4}$ & 0.4058 & $\mathbf{0 . 6 6 0 4}$ & $\mathbf{0 . 6 0 6 6}$ & 0.4795 \\
\hline Delta & 0.3196 & 0.1871 & 0.0748 & 0.1669 \\
Rank & 1 & 2 & 4 & 3 \\
\hline
\end{tabular}

Table 14

Analysis of Variance for Grey Relational Grade

\begin{tabular}{ccccccc}
\hline Source & $\mathbf{D F}^{*}$ & $\mathbf{S S}^{*}$ & $\mathbf{M S}^{*}$ & $\mathbf{F}$ & $\mathbf{P}^{*}$ & PC $^{*}$ \\
\hline Tool Rotation Speed & 3 & 0.27239 & 0.090798 & 20.61 & 0.017 & 57.9 \\
Welding Speed & 3 & 0.09155 & 0.030515 & 6.93 & 0.073 & 19.4 \\
Tool Pin Profile & 3 & 0.01482 & 0.004939 & 1.12 & 0.464 & 3.15 \\
Tool Shoulder Dia & 3 & 0.07821 & 0.026069 & 5.92 & 0.089 & 16.63 \\
Residual Error & 3 & 0.01322 & 0.004406 & & & 2.81 \\
\hline Total & 15 & 0.47018 & & & \\
\hline
\end{tabular}

${ }^{*}$ DF-Degree of Freedom; SS-Sum of Square; MS-Mean Square; PC-Percentage contribution

Using equation and response graphs, optimal values were predicted similar to GRG. Predicted values for multiple response optimizations at optimal setting of process parameters are confirmed through experimental results as shown in Table 15. Three confirmation experiments were executed to corroborate the results obtained for the performance characteristics at finest point of the process parameter. The predicted values and average values of the responses were achieved and evaluated. Table 15 shows the values of UTS and Elongation acquired through confirmation experiments that can be compared with the $2^{\text {nd }}$ and $8^{\text {th }}$ experiment in the experimental plan. Optimal values obtained were within the range of process variable which is specified earlier. When more preference is given to EL (i.e. 0.7) than UTS (i.e. 0.3) then the predicted and experimental values are compared to $2^{\text {nd }}$ and $8^{\text {th }}$ trial runs. On the other side, when UTS is more preferred (i.e. 0.7) than EL (i.e. 0.3), then a maximum value of the grade (i.e. 0.9615 ) is obtained, where UTS - 257.3 and EL - 0.75 can be given by the analysis and is presented in Table 15. 
Table 15

Predicted and Confirmation Experiments Results at optimal settings

\begin{tabular}{|c|c|c|c|c|}
\hline & \multirow{2}{*}{ In Trial $8^{\text {th }}$} & \multirow{2}{*}{ In Trial $2^{\text {nd }}$} & \multicolumn{2}{|c|}{$\begin{array}{c}\text { Optimal Parameters Settings } \\
\left(\mathrm{W}_{1}=\mathrm{W}_{2}=0.5\right)\end{array}$} \\
\hline & & & Prediction & Experimental \\
\hline Process Setting & $A_{2} B_{4} C_{3} D_{2}$ & $A_{1} B_{2} C_{2} D_{2}$ & $\mathbf{A}_{1} \mathbf{B}_{4} \mathbf{C}_{4} \mathbf{D}_{1}$ & $A_{1} B_{4} C_{4} D_{1}$ \\
\hline UTS & 249.5 & 243.85 & 248.74 & 251.4 \\
\hline EL & 0.75 & 0.75 & 0.63 & 0.60 \\
\hline Grey Relational Grade & 0.8730 & 0.78 & 0.9009 & \\
\hline & In Trial $3^{\text {rd }}$ & In Trial $7^{\text {th }}$ & \multicolumn{2}{|c|}{$\begin{array}{c}\text { Optimal Parameters Settings } \\
\left(W_{1}=0.7 ; W_{2}=0.3\right)\end{array}$} \\
\hline Process Setting & $\mathbf{A}_{1} \mathbf{B}_{3} \mathbf{C}_{3} \mathbf{D}_{3}$ & $\mathbf{A}_{2} \mathbf{B}_{3} \mathbf{C}_{4} \mathbf{D}_{1}$ & $A_{1} B_{4} C_{3} D_{2}$ & $A_{1} B_{4} C_{3} D_{2}$ \\
\hline UTS & 246.86 & 240.86 & 253.94 & 257.3 \\
\hline EL & 0.8 & 0.7 & 0.72 & 0.75 \\
\hline \multirow[t]{2}{*}{ Grey Relational Grade } & 0.8173 & 0.8261 & 0.9615 & \\
\hline & In Trial $8^{\text {th }}$ & In Trial $2^{\text {nd }}$ & \multicolumn{2}{|c|}{$\begin{array}{c}\text { Optimal Parameters Settings } \\
\left(W_{1}=0.3 ; W_{2}=0.7\right)\end{array}$} \\
\hline Process Setting & $\mathbf{A}_{2} \mathbf{B}_{4} \mathbf{C}_{3} \mathbf{D}_{2}$ & $\mathbf{A}_{1} \mathbf{B}_{2} \mathbf{C}_{2} \mathbf{D}_{2}$ & $\mathbf{A}_{1} \mathbf{B}_{4} \mathbf{C}_{4} \mathbf{D}_{1}$ & $A_{1} B_{4} C_{4} D_{1}$ \\
\hline UTS & 249.5 & 243.85 & 248.74 & 251.4 \\
\hline $\mathbf{E L}$ & 0.75 & 0.75 & 0.63 & 0.60 \\
\hline Grey Relational Grade & 0.8223 & 0.7692 & 0.9118 & \\
\hline
\end{tabular}

\section{Conclusions}

Basically, this study evaluates the welding performance of FSW by using a vertical milling machine on AA 6082 T-6 and AA 5083-O. All the experiments were run; planning and analysis were executed using Taguchi design of experiment. The purpose of the DOE method was to evaluate the optimum state of welding parameters and the importance of parameters for the performance of welding characteristics. The total experiment with 16 trials with randomized parameter was done by MINITAB 16 software. The following remarks are concluded, based on the performance of welding characteristics studied in this research work namely, UTS and EL.

1. Only three parameters, i.e. Tool Rotation Speed, WS and tool SD that mainly affects the UTS as investigated from the ANOVA table. TPP plays a non-significant role for evaluating UTS. With regard to the average response, TRS has emerged as the most significant with a contribution of $64.08 \%$, followed by WS (29.55\%); tool SD (5.67\%) and TPP can be termed as less significant for UTS. It can be concluded from the result that input parameters setting of TRS at $1200 \mathrm{rpm}$, WS at $35 \mathrm{~mm} / \mathrm{min}$ and tool SD at $16 \mathrm{~mm}$ have given the optimum results for UTS.

2. Tool rotation speed, welding/transverse speed, tool pin profile, tool SD significantly affects the EL in FSW on AA6082-T6 and AA 5083-O. With regard to the average response, TRS has emerged as the most significant with $48.29 \%$, contribution followed by WS (11.06\%); tool SD (36.71\%) and TPP can be termed as less significant. It has been concluded from the results that "input parameters setting TRS at $1200 \mathrm{rpm}$, WS at the $35 \mathrm{~mm} / \mathrm{min}$, and tool shoulder dia. at 14 $\mathrm{mm}$ have given the optimum results for elongation.

3. Multiple response optimization in FSW on AA6082-T6 and AA 5083-O has been obtained with the application of GRA and it has been found that process parameter settings of TRS at 1200 $\mathrm{rpm}$, WS of $30 \mathrm{~mm} / \mathrm{min}$, TPP of trapezoidal and the tool shoulder dia. at $14 \mathrm{~mm}$ have given the best results for simultaneous optimization of Ultimate tensile strength and Elongation. Multi response optimization provides a single parameter setting that leads to optimum welding performance in terms of two different machining characteristics collectively. From Table 15, 
an improvement of 0.0279 in the grade value has been observed. Similarly weight method has successfully changed the result, according to the requirements.

\section{References}

Akbari, M., Aliha, M. R. M., Keshavarz, S. M. E., \& Bonyadi, A. (2016). Effect of tool parameters on mechanical properties, temperature, and force generation during FSW. Proceedings of the Institution of Mechanical Engineers, Part L: Journal of Materials: Design and Applications, 1464420716681591.

Aliha, M. R. M., Shahheidari, M., Bisadi, M., Akbari, M., \& Hossain, S. (2016). Mechanical and metallurgical properties of dissimilar AA6061-T6 and AA7277-T6 joint made by FSW technique. The International Journal of Advanced Manufacturing Technology, 86(9-12), 2551-2565.

Antony, J. (2001). Simultaneous optimisation of multiple quality characteristics in manufacturing processes using Taguchi's quality loss function. The International Journal of Advanced Manufacturing Technology, 17(2), 134-138.

Bahemmat, P., Haghpanahi, M., Givi, M. K. B., \& Seighalani, K. R. (2012). Study on dissimilar friction stir butt welding of AA7075-O and AA2024-T4 considering the manufacturing limitation. The International Journal of Advanced Manufacturing Technology, 59(9-12), 939-953.

Baratzadeh, F., Handyside, A. B., Boldsaikhan, E., Lankarani, H., Carlson, B., \& Burford, D. (2011, February). Microstructural and mechanical properties of friction stir welding joints of 6082-T6 with 6063-T6. In Friction stir welding and processing VI. Held during the TMS 2011 Annual Meeting and Exhibition (pp. 229-236).

Baratzadeh, F., Widener, C. A., Lankarani, H. M., \& Burford, D. A. (2012). Methods to increase the fatigue life of friction stir lap welds in no-load transfer coupons using a retractable pin tool. Journal of ASTM International, 9(5), 1-16.

Barker, T.B. (1990). Engineering quality by design. New York: Marcel Dekker Inc.

Behnagh, R. A., Besharati Givi, M. K., \& Akbari, M. (2012). Mechanical properties, corrosion resistance, and microstructural changes during friction stir processing of 5083 aluminum rolled plates. Materials and Manufacturing Processes, 27(6), 636-640.

Byrne, D.M., \& Taguchi, S. (1987). The Taguchi approach to parameter design. Quality Progress, 20 (12), 19-26.

Çaydaş, U., \& Hasçalık, A. (2008). Use of the grey relational analysis to determine optimum laser cutting parameters with multi-performance characteristics. Optics \& Laser Technology, 40(7), 987994.

Deng, J. (1982). Control problems of grey systems. System and Control Letters, 1(5), 288-294.

Deng, J. (1989). Introduction to grey system Theory. The Journal of Grey System, 1(1), 1-24.

Esmaeili, A., Besharati Givi, M. K., \& Zareie Rajani, H. R. (2012). Experimental investigation of material flow and welding defects in friction stir welding of aluminum to brass. Materials and Manufacturing Processes, 27(12), 1402-1408.

Fukuda, T. (2001). Friction stir welding process. Welding International, 15(8), 611-615.

Gemme, F., Verreman, Y., Dubourg, L., \& Jahazi, M. (2010). Numerical analysis of the dwell phase in friction stir welding and comparison with experimental data. Materials Science and Engineering: A, 527(16), 4152-4160.

Gungor, B., Kaluc, E., Taban, E., \& Sik, A. (2014). Mechanical, fatigue and microstructural properties of friction stir welded 5083-H111 and 6082-T651 aluminum alloys. Materials \& Design, 56, 84-90.

Hassan, A. M., Almomani, M., Qasim, T., \& Ghaithan, A. (2012). Effect of processing parameters on friction stir welded aluminum matrix composites wear behavior. Materials and Manufacturing Processes, 27(12), 1419-1423.

Hassan, A. M., Qasim, T., \& Ghaithan, A. (2012). Effect of pin profile on friction stir welded aluminum matrix composites. Materials and Manufacturing Processes, 27(12), 1397-1401.

Jangra, K. K., Sharma, N., Khanna, R., \& Matta, D. (2016). An experimental investigation and optimization of friction stir welding process for AA6082 T6 (cryogenic treated and untreated) using 
an integrated approach of Taguchi, grey relational analysis and entropy method. Proceedings of the Institution of Mechanical Engineers, Part L: Journal of Materials: Design and Applications, 230(2), 454-469.

Kandasamy, J., Hussain, M. M., \& Rajesham, S. (2012). Heterogeneous friction stir welding: Improved properties in dissimilar aluminum alloy joints through insertion of copper coupled with external heating. Materials and Manufacturing Processes, 27(12), 1429-1436.

Khanna, R., Kumar, A., Garg, M. P., Singh, A., \& Sharma, N. (2015). Multiple performance characteristics optimization for Al 7075 on electric discharge drilling by Taguchi grey relational theory. Journal of Industrial Engineering International, 11(4), 459-472.

Kumar, A., \& Raju, L. S. (2012). Influence of tool pin profiles on friction stir welding of copper. Materials and Manufacturing Processes, 27(12), 1414-1418.

Kumar, P. (1993). Optimization of process variables affecting the quality of A141\% Si alloy casting produced by v-process.

Kundu, J., \& Singh, H. (2016). Friction stir welding of dissimilar Al alloys: effect of process parameters on mechanical properties. Engineering Solid Mechanics, 4(3), 125-132.

Kundu, J., \& Singh, H. (2017). Friction stir welding process: An investigation of microstructure and mechanical properties of Al Alloy AlMg4. 5Mn joint. Engineering Solid Mechanics, 5(2), 145-154.

Mathers, G. (2002). The welding of aluminium and its alloys. New York: CRC Press.

Mirjalili, A., Serajzadeh, S., Jamshidi Aval, H., \& Kokabi, A. H. (2013). Modeling and experimental study on friction stir welding of artificially aged AA2017 plates. Materials and Manufacturing Processes, 28(6), 683-688.

Mohammad Aliha, M. R., Fotouhi, Y., \& Berto, F. (2017). Experimental notched fracture resistance study for the interface of Al-Cu bimetal joints welded by friction stir welding. Proceedings of the Institution of Mechanical Engineers, Part B: Journal of Engineering Manufacture, 0954405416688935.

Okamura, H., \& Aota, K. (2004). Joining of dissimilar materials with friction stir welding. Welding international, 18(11), 852-860.

Palanivel, R., Mathews, P. K., Dinaharan, I., \& Murugan, N. (2014). Mechanical and metallurgical properties of dissimilar friction stir welded AA5083-H111 and AA6351-T6 aluminum alloys. Transactions of Nonferrous Metals Society of China, 24(1), 58-65.

Palanivel, R., Mathews, P. K., Murugan, N., \& Dinaharan, I. (2012). Effect of tool rotational speed and pin profile on microstructure and tensile strength of dissimilar friction stir welded AA5083-H111 and AA6351-T6 aluminum alloys. Materials \& Design, 40, 7-16.

Ross, P.J. (1988). Taguchi techniques for quality engineering. New York: McGraw-Hill Book Company.

Roy, R.K. (1990). A primer on Taguchi method. New York: Van Nostr and Reinhold.

Sarsilmaz, F., \& Çaydaş, U. (2009). Statistical analysis on mechanical properties of friction-stir-welded AA 1050/AA 5083 couples. The International Journal of Advanced Manufacturing Technology, 43(3), 248-255.

Sharma, N., \& Khanna, R. (2011). Optimization of process parameters of cryogenic treated D-3 in WEDM by Taguchi Approach. International Journal of Engineering Research and Applications, 1(3), 546-553.

Sharma, N., Kumar, K., Raj, T., \& Kumar, V. (2016). Porosity exploration of SMA by Taguchi, regression analysis and genetic programming. Journal of Intelligent Manufacturing, 1-8.

Shtrikman, M. M., Filatov, A. A., Gel'man, A. A., \& Ber, L. B. (2005). Special features of the formation of the joints in dissimilar aluminium alloys D19 and 1420 in the friction welding of linear joints. Welding international, 19(6), 478-483.

Soundararajan, V., Yarrapareddy, E., \& Kovacevic, R. (2007). Investigation of the friction stir lap welding of aluminum alloys AA 5182 and AA 6022. Journal of Materials Engineering and Performance, 16(4), 477-484.

Tanaka, S., \& Kumagai, M. (2010). Effect of welding direction on joining dissimilar alloys between AA5083 and A6N01 by friction stir welding. Welding International, 24(2), 77-80. 
Zna, N., Pomi, I.T., \& Zvarov, N. (2011). The tensile behavior of friction-stir-welded dissimilar aluminum alloys. Materiali in Tehnologije, 45(6), 623-626.

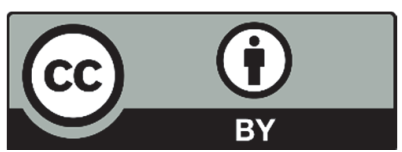

(C) 2017 by the authors; licensee Growing Science, Canada. This is an open access article distributed under the terms and conditions of the Creative Commons Attribution (CC-BY) license (http://creativecommons.org/licenses/by/4.0/). 